\title{
The Effect of the Implementation of a Negotiated Syllabus on the Reading Achievement of Iranian Intermediate-level EFL Learners
}

\author{
Abdolvahab Khademi Shamami \\ Iran University of Science \& Technology \\ (vahab.khademi@gmail.com) \\ Presented at: \\ Regional Conference on the English Language Teaching and Literature, Roudehen, Iran \\ January, 2008
}

\begin{abstract}
The present study investigated whether or not the implementation of a selective procedural Negotiated Syllabus has any effect on the reading achievement of Iranian intermediate-level EFL learners. The hypothesis assumed in this study was that the treatment would accrue no effect. The study was conducted with the participation of 61 female intermediate-level EFL learners. The participants were grouped into four classes serving the Experimental Group $(\mathrm{EG} ; \mathrm{n}=32$ ) and the Control Group (CG; $\mathrm{n}=29$ ). The learners shared a homogenous English proficiency level and background (as well as in terms of materials and instruments). The classes were randomly assigned to EG and CG. The selected element of negotiation in this study was based on the interest areas of the EG learners. An interest areas survey (IAS) based on Likert scale (from value 1 as least interesting to value 5 as most interesting) was constructed and conducted to elicit EG learners' areas of interest on the basis of which passages with reading ease of \pm 2 standard deviations (by Flesch Reading Ease score) were selected. Items scoring highest on the IAS were selected for the purpose of text selection. Interest areas were not polled in the CG and the texts given to them were arbitrarily selected. In order to observe any change in learners' reading achievement, both groups were pretested at the outset of the experiment and post-tested at the end of the experiment with a valid reading comprehension ( $\mathrm{RC}$ ) test comprising 22 multiple-choice items. A two-way twosample t-test was conducted to compare the means difference between the gain scores of the EG and CG over the two administrations of the RC test. The results indicated that the groups had performed equally well on the experiment and no statistically significant result was observed. This study was based on the natural-occurring pre-experimental intact groups framework of research design.
\end{abstract}

\section{INTRODUCTION \& BACKGROUND}

When learning (and teaching) became institutionalized, the need for a more systematic method of presenting the body of knowledge was felt at the administrative level. Even in times of tutorial instruction and before the establishment of educational and learning institutions, the tutors and mentors had a mental map of what to present. However, teaching plan was very individualistic. As the teaching enterprise was entrusted to teams of instructors and educationalists, and the number of learners increased in multiplicity, the better solution was to present the body of knowledge for everyone, that is, a rather homogeneous method of 
transferring knowledge and means of learning. To attain such a goal, syllabuses had to be devised to meet the learning and teaching requirements and demands of the subject matters and participants involved.

\section{Defining Syllabus}

Various views have been presented with regard to the definition of syllabus. As a matter fact, Pienemann (1985, as cited in Hall, 1999) defines syllabus as, "the selection and grading of linguistic teaching objectives" (p. 4). Breen (1984, as cited in Hall, 1999) considers syllabus as "a plan of what is to be achieved through our teaching and about student learning" (p. 4). Candlin (1984, as cited in Hall, 1999) provides the following summary as for the definition of syllabus:

Syllabuses are concerned with the specification and planning of what is to be learned, frequently set down in some written form as prescriptions for action by teachers and learners. They have, traditionally, the mark of authority. They are concerned with the achievement of ends, often, though not always, associated with the pursuance of particular means. (p.4)

Widdowson (1984, as cited in Nunan, 1988), on the other hand, expresses his view as such:

... the syllabus is simply a framework within which activities can be carried out: a teaching device to facilitate learning. It only becomes a threat to pedagogy when it is regarded as absolute rules for determining what is to be learned rather than points of reference from which bearings can be taken. (p. 6)

According to Yalden (1987), designing a new course requires two indispensable elements to be taken into account: (1) what is already known about the subject matter (i.e., content) and (2) learner-specific variables which vary from one setting to another (e.g., needs, wants, attitudes, knowledge of the world, etc.). Where syllabus writers may control for the former variable, they may not ensure all the elements inherent in the latter variable. Learner-specific variables, such as epistemological, (e.g., linguistic background or world knowledge), and demographic, (e.g., local (sub-)cultures, age, social class, gender, etc.), differ from one individual to another, and they are so diverse that one single syllabus may not accommodate all or most of them. Therefore, the idea of one single best syllabus for a great number of learners located in a multiplicity of demographic settings is de facto unfeasible and the need for a learner-centered syllabus is veritably warranted. In a learner-centered approach to syllabus design,

... the learner is involved, as far as possible and feasible, in the planning, implementation, and evaluation of the curriculum. This involvement is felt to increase the interest and motivation of the learners. It is also felt to be a particularly effective way of developing the learners' learning skills by fostering a reflective attitude toward the learning process. (Nunan, 1993, pp. 65-66) 
The content of the course is a facet of syllabus design in which learners can have a share and contribute part of or the whole of the materials needed for class. Concerning learners' contribution, Nunan (1999) notes that advanced learners can be given a greater sense of ownership over their learning by bringing their own authentic data. In learner-centered classes, since one method for all learners may not work efficiently, the teacher loses his/her central role as the director of the class to the facilitator (Yalden, 1987; Ballman, 1998) or a peer (Hall, 1999).

Since learners themselves own an internal natural syllabus or agenda for learning (Nunan, 1990; Nunan, 1993; Nunan, 1999; Hall, 1999), it is crucial to pay due attention to their needs, learning styles, and other learner-specific variables while initializing the construction of the syllabus. Therefore, a first task before the construction of a syllabus is the specification of learners' needs as expressed by themselves or elicited by the teacher or syllabus writers (Brindley, 1990). Needs and interests assessment is one of the bases of school curriculum and class syllabus design (Berwick, 1990). Research has shown that learners' perceptions of learning (items) differ from that of the teacher (Nunan, 1990; 1999). Furthermore, research has shown that presenting learning input on the basis of learners' interests exerts significant improvement in their learning (for a review, see Schiefele, 1996; Falakeh, 1998; Behjat, 1999). One approach to syllabus design that caters for learners' needs and interests in the construction of a syllabus a priori is negotiated syllabus.

\section{Negotiated Syllabus}

Negotiated syllabus is another approach to syllabus design and also a variant of the process syllabus. As for the origin and relevance of the term "process syllabus" Breen (1998, as cited in Breen \& Littlejohn, 2000a, p. 15) states, "[he] formulated the concept of a process syllabus in order to locate the conventional content syllabus more explicitly within and as mediated by the teaching-learning process. In addition, a process syllabus was proposed as a reference point for teachers who wished to engage students explicitly in evolving the actual curriculum of the classroom" [emphasis added].

Breen and Littlejohn (2000) assume three plains of definition for the term "negotiation": personal (which is mental, as one reads a passage or listens to discourse), interactive (as one interacts with an individual), and procedural (when parties attempt to reach an agreement). A negotiated syllabus is the exercise and practice of a learner-centered philosophy in the classroom in which the views of the learners as well as the pedagogical agenda of the teacher are satisfied through a process of give-and-take.

Six key principles can be identified as the underlying justificatinal merits of a negotiated syllabus (Breen \& Littlejohn, 2000, p.17):

- Negotiation is a means for responsible membership of the classroom community.

- Negotiation can construct and reflect learning as an emancipatory process.

- Negotiation can activate the social and cultural resources of the classroom group.

- Negotiation enables learners to exercise their active agency in learning.

- Negotiation can enrich classroom discourse as a resource for language learning. 
- Negotiation can inform and extend a teacher's pedagogic strategies.

Breen and Candlin (2001), on the contributory role of learner in negotiated syllabus, contend,

the implication [of negotiation] for the learner is that he should contribute as much as he gains, and thereby learn in an interdependent way. The learner can achieve independence by recognizing responsibility for his own learning and by sharing that responsibility with other learner and the teacher (p. 19).

Shared decision-making can be incorporated in the classroom in two approaches: a selective approach and a gradualist approach (Breen \& Littlejohn, 2000b). In the selective approach, a particular aspect of the syllabus is negotiated (such as content or assessment procedures), however, in gradualist approach, negotiation gradually envelopes deeper levels of curriculum decisions (such as moving from the negotiation on how a task will be done to negotiation of which tasks in future will be selected) (Breen \& Littlejohn, 2000b).

Any decisions that are taken will manifest themselves in the actions taken in the classroom. These may range from the immediate, moment-by-moment decisions made while learners are engaged in a task (e.g., whether they are to work in groups or alone), to the more long term planning of a language course (e.g., what will be the focus of each lessons), and through to the planning of the wider educational curriculum (e.g., links between foreign language teaching/learning and other subject areas) (Breen \& Littlejohn, 2000b) (see Figure 1 below).

Figure 1: Negotiation levels across the curriculum (Breen \& Littlejohn, 2000, p. 23).

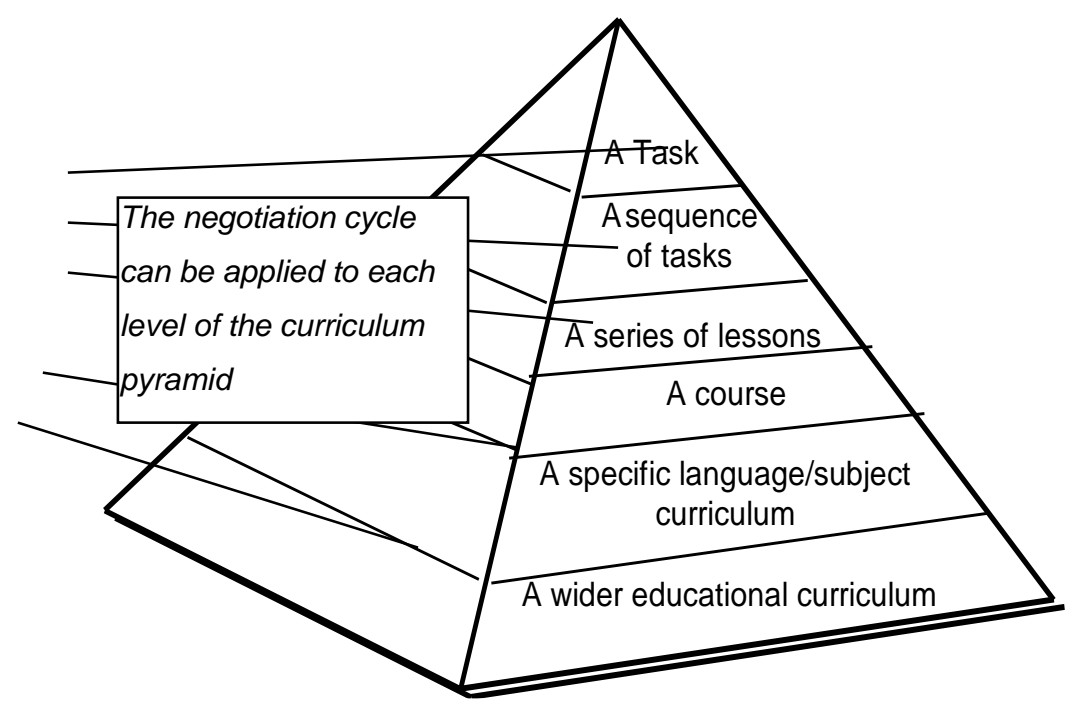

A syllabus based on the contribution of the learners can have many advantages: (1) this method can result in more autonomous learners; (2) students are more motivated; and (3) the teaching materials will have a local color because at least the texts are chosen by local students with their own tastes and interests rather than external syllabus. Furthermore, Ansari 
and Babaii (2002) maintain that such a syllabus may have the following advantages in addition to the above:

1. If every group of students has different needs, no one textbook can be a response to all differing needs,

2. Topics in a textbook may not be relevant for and interesting to all,

3. A textbook is confining, i.e., it inhibits teachers' creativity,

4. A textbook of necessity sets prearranged sequence and structure that may not be realistic and situation-friendly,

5. Textbooks have their own rationale, and as such they cannot by their nature cater for a variety of levels, every type of learning styles, and every category of learning strategies that often exist in the class, and most important of all, perhaps,

6. Teachers may find themselves as mediators with no free hand and slave, in fact, to others' judgments about what is good and what is not.

\section{METHODOLOGY}

This study has attempted to investigate whether or not the implementation of a selective procedural Negotiated Syllabus for the reading comprehension module of an English language teaching course in terms of negotiation over the areas of interest of learners as the basis on which passages would be selected has any effect on the reading ability of the Iranian intermediate-level English language learners.

\section{Design}

This study included Experimental Group, Control Group, pre-test, treatment, and posttest. There was an independent variable (areas of interest as negotiated) and dependent variable (reading ability of the learners). The CG did not receive a similar treatment to that of EG. The classes were randomly assigned as experimental group and control group. The learners, however, could not be randomly clustered to EG and CG (see Hatch \& Farhady, 1981 for this type of research design; cf., Brown, 1988 though). Therefore, the study was based on the natural occurring, pre-experimental and intact groups framework.

\section{Participants}

The current study was conducted with the participation of sixty-one female intermediate-level English language learners in the context of EFL in an English language learning center. The participants were grouped into four classes serving the Experimental Group ( $\mathrm{N}=32)$ and the Control Group ( $\mathrm{N}=29)$. The learners shared a homogenous English proficiency level and background (as well as in terms of teaching materials and instructor).

\section{Instruments}

For conducting the present study, the researcher utilized three sets of instrument as for the fulfillment of research and pedagogical requirements.

To verify any effect as of the implementation of the treatment, a reliable and valid test of reading comprehension (RC) (comprising 22 multiple-choice items) was administered to the 
Experimental Group (EG) and the Control Group (CG) at the outset of the experiment. This same reading comprehension test was administered to the EG and CG at the end of the experiment (14 sessions, 5 weeks) in order to verify any indication of learners reading comprehension progress. The items and passages were re-ordered at the second administration to cancel out testing effect on learners (though the time interval was gapped enough to ensure the non-occurrence of testing effect).

A second set of instrument utilized in the implementation of this study was an Interest Areas Survey (IAS). The IAS was administered at the beginning of the course in order to elicit learners' areas of interest on the basis of which passages of appropriate reading difficulty were collected and worked upon. The interest areas were graded on the basis of Likert scale (from value 1 as least interesting to value 5 as most interesting).

A third set of instrument utilized in this study was the passages selected on the basis of the elicited interest areas of learners in the EG attaining the highest rates and passages given to the CG whose topics were not surveyed.

\section{Procedures}

To systematically carry out the experiment, the researcher carried out certain procedures to meet the requirements of a systematic research framework.

The classes were randomly assigned to the EG and the CG.

As stated before, the element of negotiation in this study was based on the interest areas of the EG learners. In order to find out the highest-ranking interest areas of the learners objectively, an Interest Areas Survey (IAS) was constructed and on the basis of the sum of scores, the higher-ranking interest areas were selected as learner-prioritized. Following the higher-ranking interest areas of the learners, appropriate texts were collected.

The reading level of the collected texts was \pm 2 standard deviations of the mean reading ease score of the course book passages obtained through Flesch Reading Ease procedure (in Microsoft Word 2002). On the basis of obtained reading scores, passages within range of $54.16 \leq 64.3 \leq 74.44$ of reading ease were selected as teaching instruments in both groups. The passages taught in the CG class, however, were arbitrarily selected by the teacher without the control of the learners as for the interest areas (negotiations was non-existent in the CG).

Since the selected passages were authentic and were not produced for the teaching purposes, the researcher had to devise reading comprehension exercises. Five types of reading comprehension exercises were assigned to different passages: summarizing, note taking, note making, discussion, and question making. Summarizing and question making were present in all passages and assigned to all learners, but the other reading exercises were assigned to passages of appropriate genre (for example, fictional passages were assigned presentation, not discussion). These exercises were equally demanded in both groups. On the whole, 11 passages were selected and assigned to both EG and CG.

To find out whether or not this treatment would have any effect on the reading ability of the learners, the learners in both groups were pre-tested with a valid reading comprehension test comprising 22 items (Noori, 2002). The same RC test was re-ordered (to cancel out testing effect) and re-administered at the end of the treatment period to EG and CG. 


\section{Data Analysis and Interpretations}

Table 1 compares the performance of EG with that of CG on the pretest. The $t$ statistical is way smaller than the $t$ critical, therefore, it can be stated that the two groups were homogenous on reading comprehension ability at the outset of the experiment.

Table-1: t-Test Two-Sample Assuming Unequal Variances comparing EG and CG on pre-test

\begin{tabular}{lrr}
\hline & Variable 1 & Variable 2 \\
\hline Mean & 14.46875 & 14.86207 \\
Variance & 3.289315 & 4.908867 \\
Observations & 32 & 29 \\
Hypothesized Mean Difference & 0 & \\
df & 54 & \\
t Stat & -0.75407 & \\
P(T<=t) one-tail & 0.227042 & \\
t Critical one-tail & 1.673566 & \\
P(T<=t) two-tail & 0.454084 & \\
t Critical two-tail & 2.004881 & \\
\end{tabular}

Table 2 compares the performance of EG and CG on the re-administration of the RC test. As it can be seen, the two groups performed equally well on the posttest.

Table-2: t-Test: Two-Sample Assuming Unequal Variances comparing EG and CG on post-test

\begin{tabular}{lrr}
\hline & Variable 1 & Variable 2 \\
\hline Mean & 15.65625 & 15.13793 \\
Variance & 6.297379 & 4.76601 \\
Observations & 32 & 29 \\
Hypothesized Mean Difference & 0 & \\
df & 59 & \\
t Stat & 0.862502 & \\
P(T<=t) one-tail & 0.195952 &
\end{tabular}




$$
\begin{array}{ll}
\text { t Critical one-tail } & 1.671092 \\
\mathrm{P}(\mathrm{T}<=\mathrm{t}) \text { two-tail } & 0.391903 \\
\text { t Critical two-tail } & 2.000997
\end{array}
$$

To further verify whether or not the two groups would gain or lose scores between the two administrations of the $\mathrm{RC}$ test, the following formula was applied to obtain their gain scores:

$$
\text { Gain score }=(\text { post-test score })-(\text { pre-test score })
$$

Table 3 depicts the statistical results for the comparison of the gain scores of EG and those of CG.

Table-3: t-Test: Two-Sample Assuming Unequal Variances comparing gain scores of EG and CG

\begin{tabular}{lrr}
\hline & Variable 1 & Variable 2 \\
\hline Mean & 1.1875 & 0.275862 \\
Variance & 5.834677 & 7.349754 \\
Observations & 32 & 29 \\
Hypothesized Mean Difference & 0 & \\
df & 56 & \\
t Stat & 1.380995 & \\
P(T<=t) one-tail & 0.086384 & \\
t Critical one-tail & 1.672522 & \\
P $(\mathrm{T}<=\mathrm{t})$ two-tail & 0.172767 & \\
t Critical two-tail & 2.003239 & \\
\hline
\end{tabular}

The research question posed in this study was as follows:

Does the application of a Negotiated Syllabus for the reading comprehension module of an English teaching course have any effect on the reading achievement of Iranian intermediate-level EFL learners?

For the above question, the following hypothesis was assumed:

The application of a Negotiated syllabus for the reading comprehension module of an English teaching course does not have any effect on the reading achievement of Iranian intermediate-level EFL learners. 
Referring to Table 3 above, it can be seen that $t$ statistical is not large enough (it is smaller than $t$ critical) to reject the hypothesis, hence supporting the null hypothesis that: the two groups performed equally well on two tests of RC and the treatment did not accrue any statistically significant result.

\section{Discussion}

As stated above, the $t$ statistical required to reject the assumed hypothesis was not large enough ( $t$ statistical was smaller than $t$ critical) to reject the hypothesis and therefore, the hypothesis is supported. This warrants inquiry into the tentative causes of the support of the hypothesis.

One possible cause could be the effectiveness of the reading comprehension exercises which offset the interest areas variable in the EG. That is, the exercises made a balance in the two groups regardless of interest orientation.

One other possible cause as for the support of the hypothesis can be related to the proficiency level of the participants. As has widely been mentioned in the bulk of research literature, negotiated syllabus is most effective in fairly advanced English courses or in ESP contexts. The participants in the current study were at intermediate-level of proficiency, however. The latter tentative cause holds stronger cogency.

And finally, one could doubt the efficiency of a Negotiated Syllabus per se, with this caution in mind that the negotiated element in this study was the interest areas of the learners. Other approaches which take another element as for the negotiation might give a different result.

\section{Conclusion and Pedagogical Implications}

In this study, the researcher attempted to apply an element of negotiation in the external syllabus of a language course to investigate whether or not the implementation of a negotiated syllabus would have any effect on the reading achievement of Iranian intermediate-level EFL learners.

The theoretical basis for the present study was the negotiated syllabus model of syllabus design. However, this study assumes Clarke's (1991) interpretation of the negotiated syllabus where he suggests a selective and procedural approach to the design of this type of syllabus framework.

Procedural negotiation means agreement over a significant variable. The stronger version of Negotiated syllabus has often been accused of radicalism and deviation in the research literature. In the strong version of the negotiated syllabus, the total pedagogical plans of the course are based on mutual negotiation between the practitioner and learners. Negotiation, however, is a relative term which can be applied in different compartments of a teaching program. However, as has rightly been alluded to, negotiation is best carried out in contexts where: a) learners are fairy advanced and possess a sense of direction and b) learners study for certain areas of specialty (i.e., ESP) and follow a content-wise direction. In the latter case, learners can be initiators of the negotiation process because they are better informed of their academic and professional needs. Therefore, it can be concluded that negotiation is 
relative in two facets: (1) along the continuum of involved elements (from parts to the whole) and (2) the proportion of negotiation as entitled to the practitioner and the learners (i.e., the extent to which parties can enforce their initiations).

When the procedural negotiation focuses only on part(s) of the whole, it can be reconceptualized as Selective Procedural Negotiated Syllabus since certain element(s) are selected for the process of negotiation.

The element of negotiation in this research was the interest areas of learners for the reading comprehension passages.

The participants in this study were 61 female intermediate-level English language learners who were randomly assigned to Experimental Group (EG) and Control Group (CG). It should be noted that it was not possible for the researcher to randomly pool the participants and cluster them into EG and CG (this study was based on the naturally-occurring preexperimental intact groups research design framework). Nevertheless, the learners shared a homogenous language proficiency level (see Table 1) and background (as well as study materials and instructor).

The resultant statistics indicted that the two groups did equally well on the RC tests and no statistically significant difference was observed for their performance and achievement $(t$ statistical was not larger than $t$ critical to reject the hypothesis). Hence: (1) Negotiated Syllabus did not have any effect on the reading achievement of the learners; and (2) Negotiated Syllabus is not a proper model for the design of syllabus at the intermediate level of language proficiency.

\section{Pedagogical Implications}

In this study, the effect of negotiation over a syllabus element (areas of interest) between the practitioner and the learners was inquired. Statistically, though, the treatment did not accrue any significant result. Nevertheless, certain pedagogical implications could be inferred from the results of this study.

As it has been widely assumed, in the process of syllabus or curriculum design the needs and interest areas of the learners are analyzed and taken into account. This study applied such a procedure. Nevertheless, it turned out that reading achievement in both groups were statistically equal. Hence: (1) Needs analysis should cover other areas; or (2) Needs analysis is not a sure procedure at the intermediate level of language proficiency. Therefore, more caution is warranted.

Another resultant implication inferable is that negotiated syllabus may not be a proper model at intermediate level of language proficiency or in certain demographic contexts. The research literature strongly recommends the negotiated syllabus be implemented in fairy advanced courses or in courses where learners mostly focus on language for academic and professional purposes (i.e., ESP courses).

\section{References}


Ansari, H. \& Babaii, E. (2002). Universal characteristics of EFL/ESL textbooks: A step towards systematic textbook evaluation. The Internet TESL Journal, Vol. VIII, No. 2 , February 2002. Retrieved August 13, 2003 from http://iteslj.org/

Ballman, T. L. (1998). From teacher-centered to learner-centered: Guidelines for sequencing and presenting the elements of a FL lesson. In J. Harper, M. Lively, \& M. Williams (Eds.), The coming of age of profession (chap. 6, pp. 97-112). USA: Heinle and Heinle Publishers.

Behjat, F. (1999). The impact of topic interest \& dictation methods on the improvement of Iranian EFL students' listening comprehension. Unpublished MA thesis. Iran University of Science and Technology.

Berwick, R. (1990). Needs assessment in language programming: From theory to practice. In R. K. Johnson (Ed.), The second language curriculum (chap. 4, pp. 48-62). Cambridge: Cambridge University Press.

Breen, M. P \& Candlin, C. N. (2001). The essentials of a communicative curriculum in language teaching. In D. R. Hall \& A. Hewings, (Eds.), Innovation in English language teaching: A reader (chap. 1, pp. 9-26). London: Routledge.

Breen, M. P. \& Littlejohn, A. (2000). Classroom decision-making: Negotiation and process syllabuses in practice. Cambridge: Cambridge University Press.

Breen, M. P. \& Littlejohn, A. (2000a). The significance of negotiation. In M. P. Breen \& A. Littlejohn (Eds.), Classroom decision-making: Negotiation and process syllabuses in practice. Cambridge: Cambridge University Press.

Breen, M. P. \& Littlejohn, A. (2000b). The practicalities of negotiation. In M. P. Breen \& A. Littlejohn (Eds.), Classroom decision-making: Negotiation and process syllabuses in practice. Cambridge: Cambridge University Press.v

Brindley, G. (1990). The role of needs analysis in adult ESL programme design. In R. K. Johnson (Ed.), The second language curriculum (chap. 5, pp. 63-78). Cambridge: Cambridge University Press.

Brown, J. D. (1988). Understanding research in second language learning. Cambridge: Cambridge University Press.

Clarke, D.F. (1991). The negotiated syllabus: What is it and how is it likely to work? Applied Linguistics, Vol. 12 No. 1, 13-28.

Falakeh, A. (1998). The effect of topic familiarity on the listening comprehension of Iranian EFL students. Unpublished MA thesis. Tehran: Allameh Tabatabai University.

Hall, G. (1999). Redefining the syllabus: An investigation into whether syllabuses can meet learners' linguistic and social needs. Retrieved October 4, 2003 from http://www.ling.lancs.ac.uk/groups/crile/crile45Hall.pdf

Hatch, E. \& Farhady, H. (1981). Research design and statistics for applied linguistics. Tehran: Rahnama Publications. 
Noori, O. (2002). Communicative language assessment: A framed English test for Iranian pre-university students. Unpublished MA thesis. Tehran: Iran University of Science and Technology.

Nunan, D. (1988). The learner-centered curriculum: A study in second language teaching. Oxford: Oxford University Press.

Nunan, D. (1990). Hidden agendas: The role of the learner in programme implementation. In R. K. Johnson (Ed.), The second language curriculum (chap. 11, pp. 176-186). Cambridge: Cambridge University Press.

Nunan, D. (1993). Syllabus design. Oxford: Oxford University Press.

Nunan, D. (1999). Second language teaching \& learning. Boston: Heinie and Heile Publishers.

Schiefele, U. (1996). Topic interest and free recall of expository text. Learning and Individual Differences, Vol. 8 No. 2, pp. 141-160.

Yalden J. (1987). Principles of course design for language teaching. Cambridge: Cambridge University Press. 